\title{
A nucleoprotein complex mediates the integration of retroviral DNA
}

\author{
Bruce Bowerman, ${ }^{1}$ Patrick O. Brown, ${ }^{3,4}$ J. Michael Bishop, ${ }^{1-3}$ and Harold E. Varmus ${ }^{1,2}$ \\ ${ }^{1}$ Department of Biochemistry and Biophysics; ${ }^{2}$ Department of Microbiology and Immunology; ${ }^{3} \mathrm{G}$.W. Hooper Foundation, \\ University of California, San Francisco, California 94143 USA
}

\begin{abstract}
The integration of viral DNA into the host genome is an essential step in the retrovirus life cycle. To understand this process better, we have examined the native state of viral DNA in cells acutely infected by murine leukemia virus (MLV), using both a physical assay for viral DNA and a functional assay for integration activity (Brown et al. 1987). The viral DNA and integration activity copurify during velocity sedimentation, gel filtration, and density equilibrium centrifugation, indicating that viral DNA is in a large ( -160S) nucleoprotein complex that includes all functions required for integration activity in vitro. Analysis by immunoprecipitation shows that the viral capsid protein is part of the active nucleoprotein complex, but recognition of the complex by only a subset of anti-capsid sera implies that the protein is constrained conformationally. The viral DNA within this structure is accessible to nucleases; the effects of nucleases on the integrity of the complex suggest that the integration-competent particle is derived from and similar to the core of extracellular virions.
\end{abstract}

[Key Words: Retrovirus; integration; nucleoprotein complex; transposition]

Received January 13, 1989; revised version accepted February 24, 1989.

Early events in the retrovirus life cycle convert the viral RNA genome, originally within an extracellular virion, into a DNA provirus joined to a host chromosome (Fig. 1). Upon entry into a cell, viral RNA is transcribed in the cytoplasm to form a linear double-stranded DNA molecule with long terminal repeats (LTRs), and the viral DNA eventually is integrated into a chromosome (for reviews, see Varmus 1983; Varmus and Brown 1989). In addition, some of the linear DNA that enters the nucleus is converted into circular molecules with either one or two copies of the LTR.

Little is known about the intracellular structures that mediate these early events in replication. The retroviral integration reaction, however, recently has been recapitulated in vitro using cell-free extracts made from acutely infected cells as a source of precursors active for integration (Brown et al. 1987). Analysis of murine leukemia virus (MLV) integration intermediates observed in vitro has identified the linear viral DNA molecule as the immediate precursor in retroviral integration (Fujiwara and Mizuuchi 1988; Brown et al. 1989). The circular forms of viral DNA that are present in the nuclei of infected cells appear not to participate in the in vitro reaction, and their role in the virus life cycle is unresolved (Panganiban and Temin 1984a; Brown et al. 1987, 1989; Fujiwara and Mizuuchi 1988; S. Goff, pers. comm.). The viral integration protein (IN), encoded by the $3^{\prime}$ end of the pol gene, has been implicated in the

${ }^{4}$ Current address: Departments of Pediatrics and Biochemistry, Stanford University School of Medicine, Stanford, California 94305 USA. reaction through site-directed mutagenesis (Donehower and Varmus 1984; Schwartzberg et al. 1984; Panganiban and Temin 1984b|, and through demonstration of an associated endonuclease activity with the integrase protein of avian retroviruses (Duyk et al. 1983; Grandganett and Vora 1985; Grandganett et al. 1986).

We wish to improve our understanding of the structures that carry out important steps in retrovirus replication by characterizing the native state of viral DNA during its synthesis in the cytoplasm, entry into the nucleus, and integration into the genome. The intracellular structures that contain unintegrated viral DNA presumably are derived from components of the extracellular virion core, in which the viral RNA genome initially resides. The MLV virion core consists of an icosahedral protein shell, made up predominantly of multiple copies of the $30-\mathrm{kD}$ viral capsid protein (CA) encoded by the gag gene. This shell encloses the viral nucleocapsid, a complex in which two copies of the single-stranded genomic RNA are associated with the highly basic viral nucleocapsid protein, another product of gag. Also in cluded in the nucleocapsid, though less tightly associated with viral RNA, are reverse transcriptase and the integration protein encoded by pol, probably the viral protease, and perhaps other gag proteins (Dickson et al. 1985). On the basis of knowledge of the structure and components of the extracellular virion core, we have begun to examine the intracellular structures that contain unintegrated retroviral DNA and are active for integration in an in vitro assay.

Previous work has suggested that retroviral DNA in 


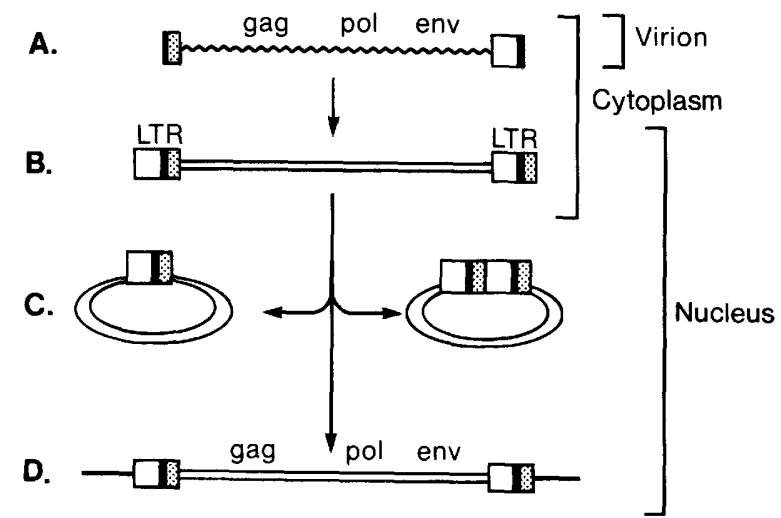

Figure 1. Nucleic acid intermediates in retroviral replication. The early events of retroviral replication convert the singlestranded, genomic RNA $(A)$ into a double-stranded DNA provirus covalently linked to the host genome $(D)$. The viral genomic RNA is present both in extracellular virion particles and in the cytoplasm of acutely infected cells immediately after viral entry. The viral RNA is reverse-transcribed in the cytoplasm into a full-length linear double-stranded DNA molecule (B), which also appears in the nucleus. In the nucleus, some of the linear DNA is converted into circular molecules with one or two LTRs $(C)$. After integration of the linear DNA into a host chromosome, the provirus $(D)$ can serve as the template for expression of progeny virus. The approximate positions of the three retroviral genes-gag, pol, and env-are indicated in structures $A$ and $D$. The compartments in which the different forms of the viral genome appear are indicated to the right.

an infected cell is tightly associated with the enzymatic machinery required for its integration (Brown et al. 1987). To characterize these putative complexes, we have made extracts from MLV-infected cells at a time when several incoming viral genomes per cell have been converted into full-length double-stranded DNA molecules. We show that this linear DNA intermediate in viral replication is part of a large, $160 \mathrm{~S}$ nucleoprotein complex that contains all the machinery required for integration activity in an in vitro assay. Immunoprecipitation and nuclease sensitivity experiments indicate that the complex is constrained conformationally and also permeable to macromolecules. The results we present are consistent with models in which the intracellular nucleoprotein complex that mediates retroviral integration is derived from and resembles the extracellular virion core.

\section{Results}

\section{$M L V D N A$ in acutely infected cells resides within a large nucleoprotein complex}

To study retroviral integration, we use a replicationcompetent derivative of MLV, called MLVsupF, which carries a bacterial supF tRNA gene in its LTRs (Lobel et al. 1985). This marker enables us to score integration events by a genetic assay in which the $\sup F$ gene in the MLV LTR suppresses amber mutations in $\lambda$ gtWES genes required for lytic growth in Escherichia coli (Brown et al. 1987). To obtain active precursors for the in vitro inte- gration reaction, $\mathrm{NIH}-3 \mathrm{~T} 3$ cells are infected by cocultivation with an MLVsupF-producing cell line. After the infection has proceeded for a period of time sufficient to generate multiple copies per cell of full-length, unintegrated viral DNA (about $18 \mathrm{hr}$ ), cell-free cytoplasmic and nuclear extracts are made (see Experimental methods). These extracts contain viral precursors that can reproduce accurately the retroviral integration reaction in vitro (Brown et al. 1987).

To determine whether the viral DNA in acutely infected cells is associated with other macromolecules, we subjected extracts to velocity sedimentation through sucrose gradients (Fig. 2), and detected the viral DNA by both a physical assay (DNA hybridization after gel electrophoresis and transfer to a nylon membrane) and a functional assay (in vitro integration activity). By both tests, the viral DNA is observed to sediment as part of a discrete complex with a sedimentation velocity of roughly $160 \mathrm{~S}$, in comparison to ribosomes (80S) and polyribosomes in the same gradients. Deproteinized unintegrated viral DNA, mixed with an extract of uninfected NIH-3T3 cells, sediments much more slowly, at about 20S (Fig. 2D), as anticipated from earlier analyses (Smotkin et al. 1975; Varmus et al. 1978). These results indicate that in an infected cell, unintegrated viral DNA resides within a large nucleoprotein complex of discrete size.

The complexes in cytoplasmic extracts typically sediment in a more discrete peak than those from nuclear extracts (see Fig. 2A,B). The circular forms of viral DNA, less abundant than the linear DNA, also sediment as large complexes. Because the linear form of DNA has been shown to be the direct precursor to MLV integration in vitro, and because complexes with circular DNA from nuclear extracts do not appear to participate in the integration reaction as studied in vitro (Fujiwara and Mizuuchi 1988; Brown et al. 1989|, we have concentrated our efforts on characterizing complexes from cytoplasmic extracts in which only the linear form of viral DNA is present at detectable levels.

\section{Integration activity copurifies with the nucleoprotein complex}

We have used three independent methods of fractionation to ask if the viral nucleoprotein complexes present in our extracts are sufficient to mediate integration in vitro. Assays of integration activity across the fractions of a sucrose gradient through which a cytoplasmic extract had been sedimented reveal that the peak for activity coincides precisely with the position of the nucleoprotein complex, as measured by detection of viral DNA (Fig. 2A,C). Furthermore, the activity in the peak fractions was not stimulated significantly by the addition of either uninfected cell extracts or extracts made from cells infected by MLV-Clone 1, a virus that does not carry the $\operatorname{supF}$ gene and therefore does not score in our assay (data not shown). These results suggest that all of the components required for integration are included in the nucleoprotein complex that contains the viral DNA. 

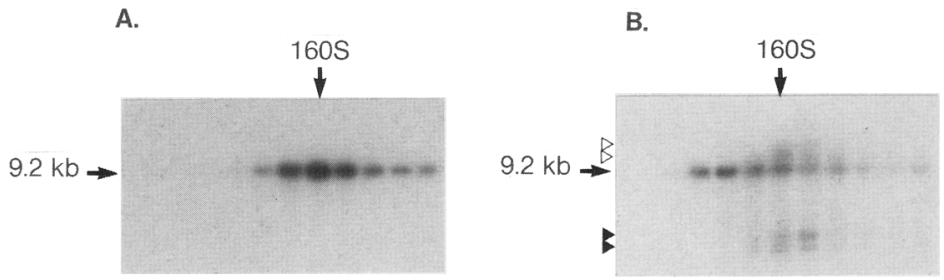

c.

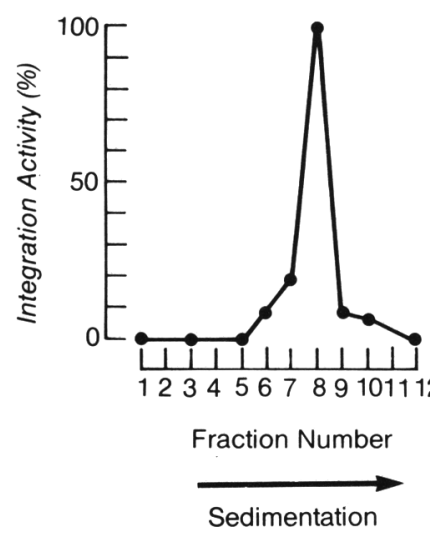

D.

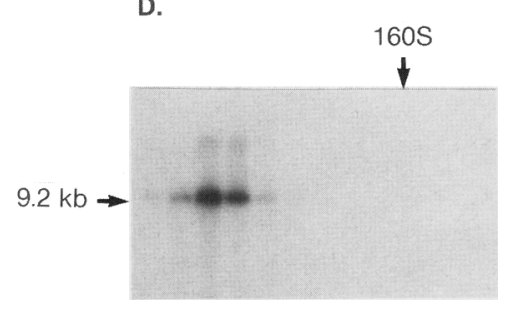

Figure 2. Retroviral DNA and integration activity cosediment in sucrose gradients. Eighteen hours after cocultivation of an MLVsupF-producing cell line with uninfected NIH-3T3 cells, cell-free extracts were prepared as described in Experimental methods, and $0.5-\mathrm{ml}$ aliquots were loaded onto $15-30 \%$ sucrose gradients, which were then centrifuged at $35,000 \mathrm{rpm}$ for $3 \mathrm{hr}$ at $4^{\circ} \mathrm{C}$ in a Beckman SW-4l rotor. The gradients were divided into 12 fractions of $1 \mathrm{ml}$ each. Viral DNA samples prepared from each fraction (see Experimental methods) were resolved by gel electrophoresis in $0.8 \%$ agarose and transferred to a nylon membrane. MLV DNA was identified by hybridization, using as a probe the plasmid p8.2 (a complete, permuted clone of circular MLV DNA with one LTR) labeled by nick-translation. Arrows indicate the fulllength $9.2-\mathrm{kb}$ linear viral DNA, the $160 \mathrm{~S}$ peaks of polysome profiles determined by absorbance at $260 \mathrm{~nm}$ during the fractionation, and the direction of sedimentation. Integration activity is expressed as a percentage of the most active fraction /the numbers of recombinant plaques are presented in Table 1 in Experimental methods). (A) Viral DNA from gradient fractions after sedimentation of a cytoplasmic extract. $(B)$ Viral DNA from gradient fractions after sedimentation of a nuclear extract. The open arrowheads indicate relaxed circles with one and two LTRs, and the closed arrowheads indicate supercoiled circles. (C) Integration activity across the gradient fractions shown in $A$; the fraction numbers in $B$ correspond to the lanes in $A .(D)$ The profile of viral DNA obtained after sedimentation of an uninfected cytoplasmic extract to which purified cytoplasmic viral DNA had been added.

We obtained similar results using gel-exclusion column chromatography (Fig. 3). When a cytoplasmic extract was passed through a gel filtration column with an exclusion limit of $5 \times 10^{6}$ daltons, the DNA-containing complexes appeared in the void volume, coincident with the integration activity. By comparison to serial twofold dilutions of the extract loaded onto the column, we estimate that we recovered between $25 \%$ and $50 \%$ of the viral DNA (Fig. 3B). A pool of the peak fractions was $36 \%$ as active for integration in vitro as the extract that was loaded onto the column /see Table 1). Thus, the recovered amounts of activity and viral DNA were roughly the same. The fractionation achieved by the column resulted in more than a thousandfold reduction in protein concentration (data not shown, but see absorbance profile, Fig. 3A), providing substantial purification. Again, addition of crude extracts did not augment the activity of the partially purified complexes.

As a further test of the association of integration activity with the nucleoprotein complex, we characterized nuclear extracts by density equilibrium centrifugation in nonionic density gradients. Analysis of gradient fractions for the presence of viral DNA showed that both the linear and circular forms produce bands at a density characteristic of a nucleoprotein complex (Fig. 4). The peak of integration activity again coincided with the position of the nucleoprotein complex (Fig. 4B), and the concentration of activity achieved (see Table 1) was comparable to that of the viral DNA (compare the intensities of bands representing the full-length linear DNA in the load and in the peak fraction of the gradient in Fig. 4A). The copurification of integration activity with the nucleoprotein complex during velocity sedimentation, gel-exclusion column chromatography, and density equilibrium centrifugation argues strongly that the nucleoprotein complex that contains the viral DNA includes all the machinery required for integration into the host genome.

After density equilibrium centrifugation, the DNAcontaining complexes from cytoplasmic extracts banded at densities similar to those of complexes from nuclear extracts but lost over $90 \%$ of their integration activity. We have been unable to restore integration activity reproducibly by the addition of crude extracts (data not shown|. Currently, we are unable to explain this difference in behavior between cytoplasmic and nuclear extracts.

The viral capsid protein is a component of the nucleoprotein complex

Polyclonal antisera against the viral capsid protein, the major structural component of extracellular virion cores 
Figure 3. Copurification of the nucleoprotein complex and integration activity during gel-exclusion column chromatography. After fractionation of MLVsupF-infected NIH-3T3 cells, $5 \mathrm{ml}$ of cytoplasmic extract were passed through a 200-ml BioRad A5M column. Next, $1.5-\mathrm{ml}$ fractions were collected and aliquots were used to prepare viral DNA and assay integration activity. $|A|$ (๑) Integration activity expressed as percentage of the most active fraction. Fraction 45 is the first point with detectable integration activity, and activity is plotted for fractions 10,40,45-60, 70, 80, and 100. (이 Absorbance, with units shown to the right. For primary data from integration assays of the extract loaded onto the column and a pool of fractions $45-60$, see Table $1 .(B)$ Viral DNA samples from fractions $45-60$ are to the left, after electrophoresis and hybridization as described in Fig. 2. Flanking fractions did not contain detectable levels of viral DNA (data not shown). To the right are serial twofold dilutions of viral DNA from the cytoplasmic extract that was loaded onto the column.

(see introductory section), coprecipitated both viral DNA (Fig. 5) and integration activity (Table 2) from cytoplasmic extracts of cells infected with MLVsupF, indicating that the viral capsid protein is part of the integration-competent nucleoprotein complex. However, two of the tested anti-capsid sera were unable to coprecipitate the viral DNA, even though they recognize the capsid protein from denatured virions when assayed under identical conditions (data not shown). Recognition of the nucleoprotein complex by only a subset of antisera suggests that some capsid epitopes may not be exposed. As evidenced by the presence of integration activity in the immune complex pellets, none of the antisera tested inhibited the ability of the complexes to integrate into target DNA. In addition, pretreating the extracts with quantities of antisera that are sufficient to precipitate the complexes had no effect on integration activity (data not shown).

Genetic analyses have demonstrated a role for the viral integration protein in retrovirus integration (see introductory section), but we have been unable to immunoprecipitate complexes with antisera that recognize the integration protein, reverse transcriptase, or both (data not shown). Because the nucleoprotein complex appears to include all of the activities required for integration, we suspect that at least the integration protein is included in these complexes but is inaccessible to the antibodies.

\section{A.}
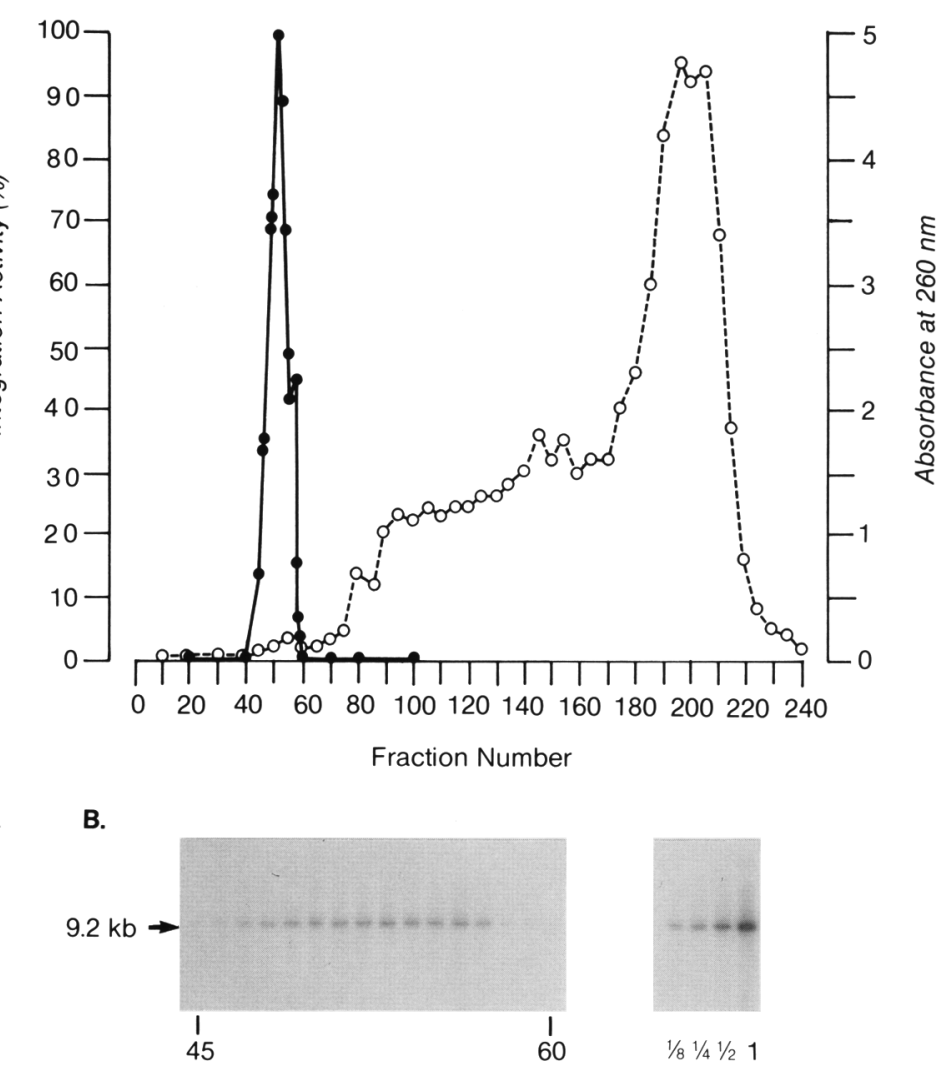

Viral DNA in nucleoprotein complex is accessible to nuclease

We have used nucleases as probes of the arrangement of DNA and protein in the complex. First, infected cell extracts were purified partially by gel filtration through a BioRad A5M column (as described in Fig. 3) and incubated with micrococcal nuclease in the presence of $\mathrm{Ca}^{2+}$. Under these conditions, much of the viral DNA was digested (see Fig. 6A). Disappearance of full-length viral DNA, measured by densitometry of the $9.2-\mathrm{kb}$ band remaining at each time point, roughly paralleled the loss of integration activity (Fig. 6B), suggesting that active complexes are similarly sensitive to nuclease digestion. As a control, complexes were treated with micrococcal nuclease in the absence of $\mathrm{Ca}^{2+}$ and shown to retain full activity throughout the time of incubation (Fig. 6B). Furthermore, addition of complexes extensively digested by micrococcal nuclease to extracts containing untreated complexes did not inhibit the integration activity of the untreated extracts (data not shown). Thus, the loss of integration activity appears to be due to cleavage of viral DNA and not to inhibition by products of the nuclease treatment.

The pattern of degradation of viral DNA by micrococcal nuclease shows a general lack of specificity. The degraded viral DNA, when visualized by hybridization to a probe for the entire viral genome, consists of a broad 
Table 1. Integration assays: recovery of target DNA and number of recombinant plaques scored

\begin{tabular}{|c|c|c|}
\hline Experiment & $\begin{array}{l}\text { Packaging } \\
\text { efficiency } \\
\text { (pfu/ } / \mu \mathrm{g} \lambda \\
\text { target DNA) }\end{array}$ & $\begin{array}{l}\text { Recombinant } \\
\text { plaques }\end{array}$ \\
\hline \multicolumn{3}{|l|}{$\begin{array}{l}\text { Velocity sedimentation } \\
\text { (Fig. 2C) }\end{array}$} \\
\hline Fraction 6 & $1.0 \times 10^{8}$ & 2 \\
\hline Fraction 7 & $3.0 \times 10^{8}$ & 27 \\
\hline Fraction 8 & $1.2 \times 10^{8}$ & 64 \\
\hline Fraction 9 & $2.5 \times 10^{8}$ & 22 \\
\hline Fraction 10 & $1.1 \times 10^{8}$ & 3 \\
\hline \multicolumn{3}{|l|}{ Gel filtration (Fig. 3) } \\
\hline Cytoplasmic extract load & $4.3 \times 10^{7}$ & 467 \\
\hline Pool of fractions $45-60$ & $6.2 \times 10^{7}$ & 239 \\
\hline \multicolumn{3}{|l|}{ Density gradient (Fig. 4) } \\
\hline Nuclear extract load & $3.3 \times 10^{7}$ & 357 \\
\hline Fraction 5 & $2.0 \times 10^{7}$ & 285 \\
\hline Fraction 6 & $3.4 \times 10^{7}$ & 1687 \\
\hline Fraction 7 & $3.3 \times 10^{7}$ & 139 \\
\hline Fraction 8 & $3.2 \times 10^{7}$ & 61 \\
\hline Fraction 9 & $2.4 \times 10^{7}$ & 25 \\
\hline \multicolumn{3}{|l|}{$\begin{array}{l}\text { Micrococcal nuclease } \\
\text { (Fig. 6B) }\end{array}$} \\
\hline $0 \mathrm{~min}$ & $7.7 \times 10^{7}$ & 332 \\
\hline $0.5 \mathrm{~min}$ & $7.3 \times 10^{7}$ & 126 \\
\hline $1.0 \mathrm{~min}$ & $4.0 \times 10^{7}$ & 40 \\
\hline $2.5 \mathrm{~min}$ & $1.1 \times 10^{8}$ & 52 \\
\hline $5.0 \mathrm{~min}$ & $6.3 \times 10^{7}$ & 11 \\
\hline $7.5 \mathrm{~min}$ & $1.1 \times 10^{8}$ & 11 \\
\hline $10.0 \mathrm{~min}$ & $2.1 \times 10^{8}$ & 9 \\
\hline $30.0 \mathrm{~min}$ & $2.0 \times 10^{8}$ & 1 \\
\hline $60.0 \mathrm{~min}$ & $7.5 \times 10^{6}$ & 0 \\
\hline
\end{tabular}

The numbers shown are averages for either duplicate or triplicate assays. Integration reactions were done with $100 \mu \mathrm{l}$ of sample in a total reaction volume of $150 \mu \mathrm{l}$. Control reactions showed that the levels of sucrose and Nycodenz present in some samples did not affect integration activity (data not shown). Packaging efficiency (pfu/ $\mu$ g target DNA) reflects the recovery of phage DNA during in vitro packaging. Using this value, the number of recombinant plaques can be normalized to give the percentages shown in Figs. 2, 3, 4, and 6.

smear that becomes smaller in size with increasing time of digestion (Fig. 6A and 7A). To substantiate the absence of products of discrete sizes after nuclease digestion, we mixed Rat-1 nuclei with complexes purified partially by gel filtration and treated the mixture with micrococcal nuclease. Digestion of cellular chromatin generated the expected nucleosome ladder (Fig. 7B), but the viral DNA again was degraded into a broad smear that bore no resemblance to a nucleosome ladder (Fig. 7A). The only indication of specific sensitivity to nuclease cleavage was the early appearance of a band representing a roughly $0.6-\mathrm{kb}$ fragment of viral DNA discernible after hybridization to a probe for the entire viral genome (Fig. 7A). This band was more prominent-relative to the band representing full-length 8.8 -kb viral DNA - when detected by hybridization to a probe specific for the viral LTR sequences (Fig. 7C). Thus, al-

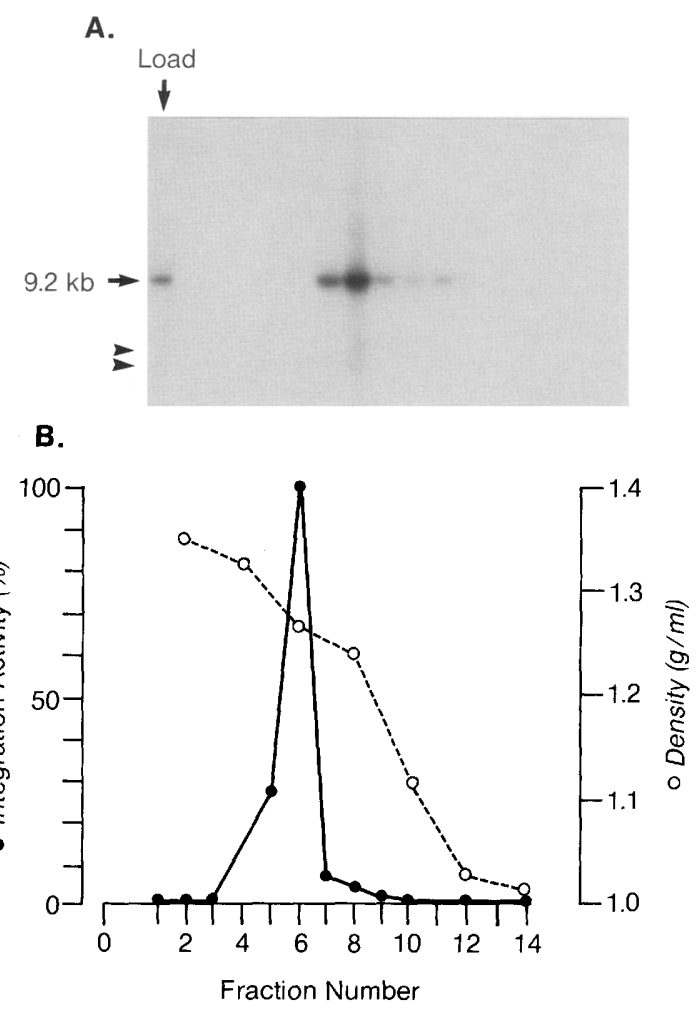

Figure 4. Retroviral DNA and integration activity band at a density appropriate for a nucleoprotein complex. After infection of NIH-3T3 cells with MLVsupF, nuclear extracts were made by breaking open nuclei and pelleting the cellular chromatin (see Experimental methods). The nuclear extract supernatant was mixed with Nycodenz, a nonionic density gradient medium, to form a $12-\mathrm{ml}$ step gradient, which was centrifuged for $8 \mathrm{hr}$ at $50,000 \mathrm{rpm}$ at $4^{\circ} \mathrm{C}$ in a Beckman Ti-50 fixed-angle rotor. The gradient was divided into 14 fractions of $0.85 \mathrm{ml}$ each, and aliquots were removed for measuring viral DNA, in tegration activity, and density. (A) Viral DNA in gradient fractions. Viral DNA from the extract used to make the gradient is shown at the left (lane designated 'Load') for comparison with the peak fractions. Arrow indicates the full-length $9.2-\mathrm{kb}$ linear viral DNA, and the arrowheads indicate the supercoiled circles with one and two LTRs. $(B)$ Plots of integration activity $(\bullet)$ and density (o) across the gradient. Purified DNA bands at 1.13 to $1.17 \mathrm{grams} / \mathrm{ml}$ and most proteins at densities between 2.0 and $3.0 \mathrm{grams} / \mathrm{ml}$. The fraction numbers designated in $B$ correspond to the lanes above in $A$. For primary data from integration assays, see Table 1.

though the majority of the viral DNA in the complex appears to be uniformly sensitive to micrococcal nuclease, at least some of the viral LTR sequences are associated with a more specialized structure.

To examine further the effects of nuclease treatment on the structure of these complexes, we incubated complexes purified partially by gel filtration with a mixture of BgIII and BamHI restriction endonucleases (for which there are a total of seven sites in the viral DNA), and then analyzed them by velocity sedimentation in sucrose gradients. Analysis of gradient fractions for the presence and state of viral DNA showed that the complexes could still sediment as discrete particles, even 

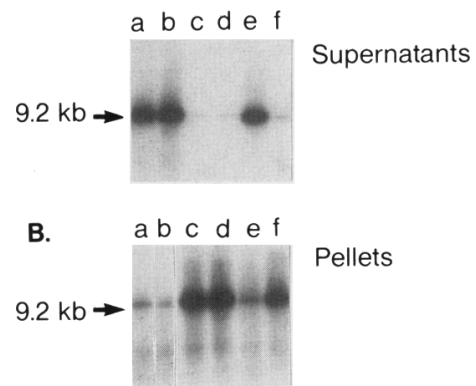

Figure 5. Coprecipitation of viral DNA with antisera that recognize the viral capsid protein. To identify viral components of the retroviral nucleoprotein complex, antisera that recognize the virion capsid protein were tested for their ability to precipitate the nucleoprotein complex and integration activity (see Table 2 for integration activity data). For each immune precipitation, $300 \mu \mathrm{l}$ of cytoplasmic extract from cells acutely infected by MLVsupF and $5 \mu \mathrm{l}$ of antiserum were mixed on ice in buffer A with $0.5 \%$ NP- 40 , and immune complexes were formed by the addition of fixed $S$. aureus cells. The complexes were pelleted by centrifugation, and the supernatants were saved for analysis of viral DNA and integration activity. The pellets were washed three times with buffer A containing $0.5 \%$ NP- 40 , and the washed pellets were resuspended in the same buffer and also analyzed for viral DNA and integration activity. $(A)$ Viral DNA from supernatants after removal of immune complexes. The arrow designates the full-length 9.2-kb linear viral DNA. Samples: Goat nonimmune serum (lane a); goat anti-MLV (whole virus) serum (lane $b$ ); goat anti-MLV capsid serum \#1 (lane $c$ ); rabbit anti-MLV capsid serum \# 1 (lane $d$ ); rabbit antiMLV capsid serum \#2 (lane $e$ ); goat anti-MLV capsid serum \#2 (lane $f$ ). (B) Viral DNA from immune complex pellets. Lanes are same as in $A$. Viral DNA samples were prepared and analyzed as described in Fig. 2.

when the viral DNA had been cleaved at several sites, generating fragments as small as $1 \mathrm{~kb}$ in size (Fig. 8). Complexes that were mock-treated for the same period of time sedimented to the same position in control gradients (data not shown). Although we have seen sometimes a slight staggering of smaller fragments toward the

Table 2. Coprecipitation of retroviral integration activity by anti-capsid antiserum

\begin{tabular}{|c|c|c|}
\hline Experiment & 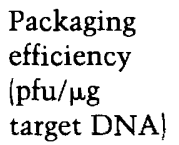 & $\begin{array}{l}\text { Recombinant } \\
\text { plaques }\end{array}$ \\
\hline \multicolumn{3}{|c|}{ Immune precipitations } \\
\hline \multicolumn{3}{|c|}{ Goat nonimmune serum } \\
\hline Supernatant & $8.3 \times 10^{7}$ & 240 \\
\hline Pellet & $2.5 \times 10^{7}$ & 3 \\
\hline \multicolumn{3}{|c|}{$\begin{array}{l}\text { Goat anti-MLV capsid } \\
\text { serum \#1 }\end{array}$} \\
\hline Supernatant & $4.5 \times 10^{7}$ & 9 \\
\hline Pellet & $2.5 \times 10^{6}$ & 90 \\
\hline
\end{tabular}

Integration reactions were done with $100 \mu \mathrm{l}$ of sample in a total volume of $150 \mu \mathrm{l}$. See Fig. 5, Table 1, and Experimental methods for descriptions of immunoprecipitation procedures and in vitro integration assays.
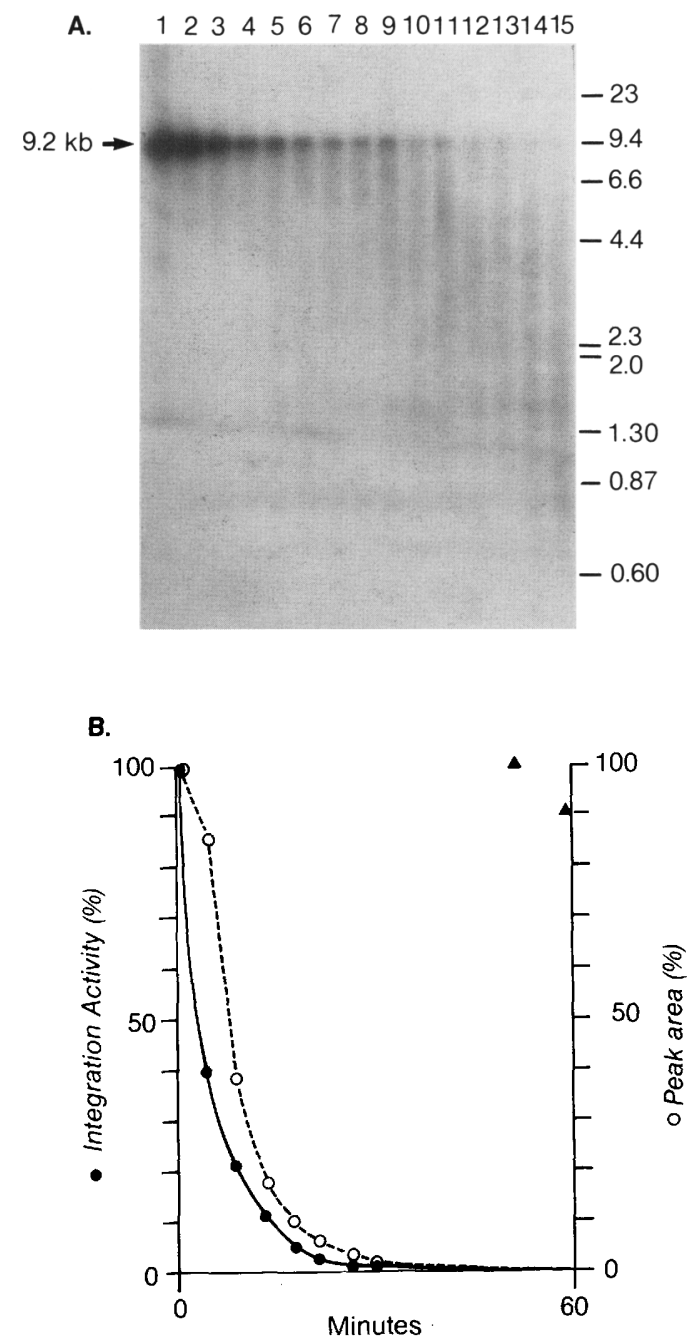

Figure 6. Viral DNA in the integration-competent nucleoprotein complex is accessible to micrococcal nuclease. A cytoplasmic extract made from cells acutely infected by MLVsupF was purified partially by gel filtration (as described in Fig. 3). A total of $3.5 \mathrm{ml}$ of the partially purified extract was incubated on ice with micrococcal nuclease in the presence of $1 \mathrm{mM} \mathrm{CaCl}$. Digestion was stopped by removal of samples at the times indicated below; these were adjusted to 2 mM EGTA and analyzed for viral DNA and integration activity. The relative quantities of full-length viral DNA remaining at each time point were determined by densitometry to obtain peak areas of the $9.2-\mathrm{kb}$ band (indicated by arrow) remaining at each time point. $(A)$ Viral DNA from time course of micrococcal nuclease incubation, after electrophoresis in $1.0 \%$ agarose and hybridization, as described in Fig. 2. (Lanes 1-15) Digestions stopped at 0 (before addition of $\left.\mathrm{CaCl}_{2}\right), 0.5,1.0,2.5,5.0,7.5,10,12.5,15,17.5,20$, 30,45 , and $60 \mathrm{~min}$. Size markers (in kilobases) are to the right. $(B)$ Plot of integration activity $(\bullet)$ and peak area $(0)$ after scanning the $9.2-\mathrm{kb}$ band shown in $A$. Time points plotted correspond to lanes 1-7 shown in $A$. ( $\mathbf{\Delta})$ Integration activity of control samples incubated on ice with micrococcal nuclease in the absencc of $\mathrm{CaCl}_{2}$ for 30 and $60 \mathrm{~min}$. For the primary data from integration assays, see Table 1 . 


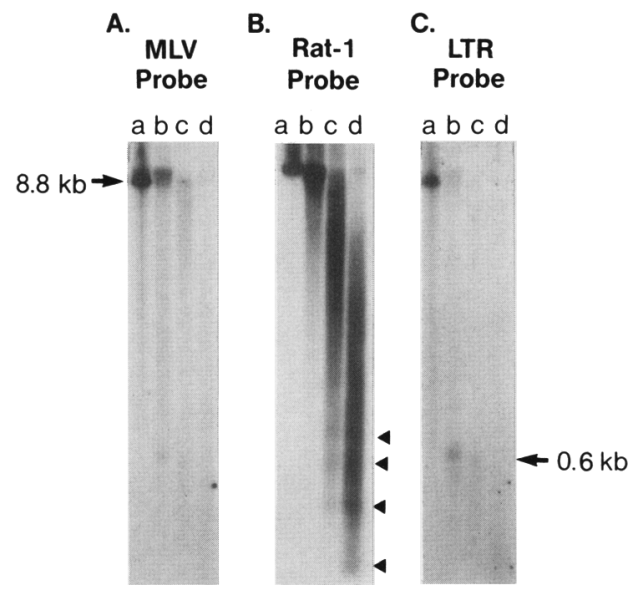

Figure 7. Viral DNA in the nucleoprotein complex differs from chromatin in its pattern of sensitivity to micrococcal nuclease. Nuclei from uninfected Rat-1 cells, prepared as described in Experimental methods, were resuspended in buffer B and mixed with an equal volume of cytoplasmic extract made from cells acutely infected by MLV-Clone 1 la wild-type MLV strain that lacks the $\sup F$ gene) and purified partially by gel filtration through a BioRad A5M column (see Fig. 3). The mixture was adjusted to $1 \mathrm{mM} \mathrm{CaCl}$ and incubated on ice with micrococcal nuclease. Digestion was stopped by addition of $2 \mathrm{~mm}$ EGTA (final concentration) to aliquots removed at the times indicated. DNA was prepared and samples resolved by gel electrophoresis in $1.5 \%$ agarose. After transfer to a nylon membrane, sequential hybridization to nick-translated probes was used to distinguish viral and Rat- 1 chromosomal sequences. (Lanes $a-d) 0,5,20$, and 40 min time points. (A) Hybridization to the probe for the entire MLV genome (made by nick-translation of the plasmid p8.2). An arrow indicates full-length $8.8-\mathrm{kb}$ linear viral DNA. (B) Hybridization to nick-translated Rat-1 chromosomal DNA. The closed arrowheads indicate the nucleosome ladder generated by nuclease digestion of cellular chromatin. $(C)$ Hybridization to the probe specific for viral LTR sequences (made by nick-translating the plasmid pGEMLTR, a permuted clone of the MLV LTR). An arrow indicates the $\sim 600$-bp fragment specific for the LTR probe.

top of the gradient in such experiments (data not shown), the sedimentation properties of the complex appear to be largely unaffected by cleavage of the viral DNA within them.

\section{Discussion}

The principal result we present here is that unintegrated retroviral DNA isolated in its native state from acutely infected cells resides within a large nucleoprotein complex. This complex sediments at $160 \mathrm{~S}$ and carries with it all of the activities necessary for integration in vitro. Copurification of the complex and integration activity also is observed during gel-exclusion column chromatography and density equilibrium centrifugation.

These results suggest that retroviral DNA within infected cells remains associated with the protein machinery responsible for integration into the host genome. Such a solution to the requirement for integration is consistent with the idea that retroviruses bring into infected cells all the activities needed for reverse transcription and integration (Varmus and Brown 1989). A tight association of the viral nucleic acids with the viral replication machinery avoids any dilution of essential factors in the host cytoplasm and nucleus, allowing the virus to perform essential steps in replication with only a limited number of the necessary proteins. If any host components participate in these events, presumably they do so through association with these complexes.

Purification of the active complex eventually should allow the direct identification of its components. However, the extracts we make from acutely infected cells exhibit substantial variability in their activity, with as few as $0.1 \%$ to as many as $50 \%$ of the complexes present in an extract being active for integration in vitro (Brown et al. 1987, 1989; Fujiwara and Mizuuchi 1988; P. Pryciak and P. Brown, unpubl.). Because about $1 \%$ of the complexes present in the extracts used here were active in vitro, conclusions based on direct purification of the entire population might be misleading. Instead, we have focused initially on indirect methods of analysis that allow us to examine active complexes by the use of an in vitro assay for integration activity. In these experiments, we also have examined the entire population present in cell-free extracts by detection of the viral DNA after gel electrophoresis. In general, the active population and the

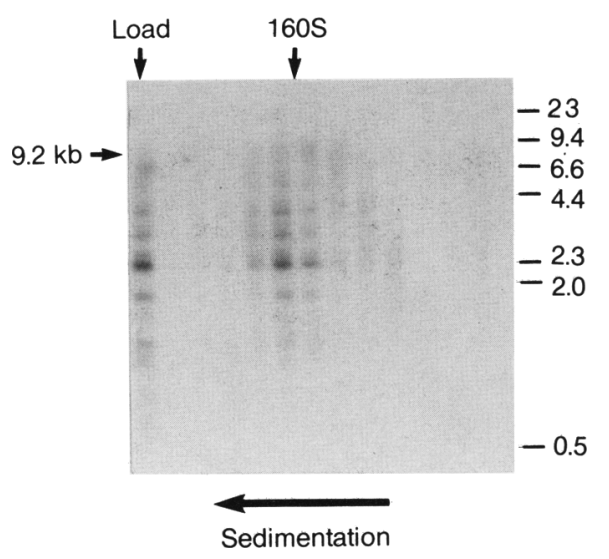

Figure 8. Cleavage of viral DNA in the nucleoprotein complex does not affect its sedimentation behavior in sucrose gradients. Cytoplasmic extract made from cells acutely infected by MLVsupF was purified partially by gel filtration through a BioRad A5M column (see Fig. 3) and digested on ice with BgIII and $B a m H I$ restriction enzymes for $3 \mathrm{hr}$. The digestion was stopped by the addition of $10 \mathrm{~mm}$ EDTA. After removing an aliquot for the lane designated 'Load', the remaining extract was subjected to velocity sedimentation in a $15-30 \%$ sucrose gradient (see Experimental methods). The gradient was divided into 13 fractions of $1 \mathrm{ml}$ each. Viral DNA was prepared from each fraction, resolved by gel electrophoresis in $1.0 \%$ agarose, and analyzed as described in Fig. 2. The arrow indicates the position of full-length 9.2 -kb linear viral DNA. Size markers (in kilobases) are to the right. The $160 \mathrm{~S}$ arrow indicates the position of the nucleoprotein complex in a control gradient in which the extract was mock-treated. Direction of sedimentation is indicated by the arrow at the bottom. 
total population show similar behavior. The one exception has been our inability to concentrate integration activity when we band complexes from cytoplasmic extracts in density equilibrium gradients. This is in contrast to banding nuclear complexes in density gradients, in which case both integration activity and the nucleoprotein complex are concentrated.

Immunoprecipitation of integration-competent particles has enabled us to show that the viral capsid protein is one component of the active complex. The capsid protein of MLV is the major structural component of the extracellular virion core, in which it forms the icosahedral shell that encases the viral nucleocapsid. The ability to precipitate the nucleoprotein complex and integration activity with antisera that recognize capsid suggests that, after entry into the cell and completion of reverse transcription, unintegrated viral DNA remains associated with a structure that still retains at least some of the capsid protein. In addition, the failure of some anti-capsid sera to precipitate the complexes implies that conformational constraints obscure some antigenic determinants.

The presence of at least some of the capsid in the nucleoprotein complex is of interest because of the role this protein is thought to play in the inability of certain strains of MLV, called N-type and B-type viruses, to replicate in cell lines derived from particular inbred strains of mice, a phenomenon termed $F V-1$ restriction (Jolicoeur 1979|. In restricted infections, virus can enter the cell and synthesize viral DNA but does not appear capable of establishing a provirus. N- and B-tropism map to the viral capsid protein; if the coding sequences for capsid are interchanged between an $\mathrm{N}$ - and a B-type virus, their tropism is reversed (Jolicoeur 1979; DesGroseillers and Jolicoeur 1983). The presence of the viral capsid protein in the nucleoprotein complex that contains unintegrated viral DNA raises the interesting possibility that $F V-1$ restriction may operate through an interaction with the capsid protein components of the nucleoprotein complex that contains the viral DNA inside infected cells.

The use of nucleases as a probe of structure has revealed that much of the unintegrated viral DNA in these complexes is accessible to exogenous macromolecules. The pattern of degradation of the viral DNA within the complexes shows little pattern, unlike the nucleosome ladder generated by nuclease treatment of host chromatin. At least some of the viral LTR sequences, however, show a more specific sensitivity to treatment with micrococcal nuclease. The LTRs are the only viral sequences required in cis for integration, and their pattern of sensitivity to micrococcal nuclease suggests the presence of specialized structures associated with LTR sequences.

Viral DNA in the complex also is accessible to the restriction endonucleases BgIII and BamHI, but complexes that have been cleaved at several sites have unaltered sedimentation properties. This result argues against models for the structure of these complexes in which large stretches of viral DNA are left essentially free, with the protein components arranged only at the ends of the viral DNA. Models in which the proteins and viral DNA are in some type of 'beads on a string' arrangement also would be inconsistent with these results. The viral DNA in the complex is not assembled into nucleosomes, in contrast to host chromatin (Kornberg 1977; Felsenfeld 1978) and papovavirus minichromosomes (Griffith 1975; Muller et al. 1978). More consistent with our results are models in which the viral DNA resides within a protein shell that is permeable to nucleases. Given that the MLV capsid protein forms an icosahedral shell in the virion core and appears to be a component of the integration-competent complex, we favor this possibility. The simplest view is that the integration-competent complex is similar to and derived from the extracellular virion core. However, we cannot rule out models in which the viral DNA is on the outside of a nucleoprotein complex that remains intact after DNA cleavage because of other interactions. We hope to resolve these issues by electron microscopy of purified complexes.

The best-understood example of DNA recombination that resembles retroviral integration is the nonreplicative transposition reaction of the bacteriophage $\mathrm{Mu}$. Reconstitution in vitro of the $\mathrm{Mu}$ transposition reaction has shown that a highly ordered and tightly bound complex of DNA and protein is required for activity (Craigie and Mizuuchi 1985; Surette et al. 1987). Highly ordered nucleoprotein complexes also are involved in a variety of other functions that involve precise manipulation of DNA. Examples include the multicomponent arrangements of proteins at replication origins in $E$. coli and phages $\lambda$ and T4, and the intasome intermediate in the integration reaction of phage $\lambda$ (for reviews, see Alberts 1984; Echols 1986; Bramhill and Kornberg 1988; Friedman 1988). Further characterization of the integration-competent nucleoprotein complexes described here may prove useful in designing attempts to reconstruct MLV integration activity with purified components, and contribute to a description of the molecular events that constitute retroviral integration. Finally, a better understanding of retroviral integration should prove relevant to studies of retrotransposons, such as Ty elements in yeast, which also employ a nucleoprotein complex to integrate into the host genome (Boeke et al. 1985; Eichinger and Boeke 1988), but which do not have an extracellular phase in their transposition cycle (for review, see Roeder and Fink 1983).

\section{Experimental methods}

Cell culture, cellular extracts, and integration reactions

Procedures for infection of NIH-3T3 cells by cocultivation with MLVsupF-producing NIH-3T3 cells, harvesting and fractionation of infected cell cultures into cytoplasmic and nuclear extracts, and integration reactions were nearly the same as described previously (Brown et al. 1987). However, cells were harvested at $18 \mathrm{hr}$ postinfection instead of $24 \mathrm{hr}$, and integration reactions included $1.0 \mu \mathrm{g}$ of $\lambda$ target DNA instead of $1.4 \mu \mathrm{g}$. Integration reactions were normalized for recovery of the target DNA after in vitro packaging of the DNA recovered from reac- 
tions. In Figures 2, 3, 4, and 6, integration activity was plotted as a percentage of the most active fraction in each experiment. Recovery of target DNA and the number of recombinant plaques scored are indicated in Table 1.

\section{DNA analysis}

For preparation of DNA, samples were adjusted to $10 \mathrm{~mm}$ EDTA, $0.5 \% N$-lauroyl sarcosine, and $0.5 \mathrm{mg} / \mathrm{ml}$ of proteinase $\mathrm{K}$; incubated for $2 \mathrm{hr}$ at $55^{\circ} \mathrm{C}$; extracted twice with phenol/chloroform $(1: 1)$; and precipitated by adjusting the final salt concentration to $300 \mathrm{~mm}$ with $\mathrm{NaOAc}$, adding $4 \mu \mathrm{g}$ of yeast RNA carrier and 2.5 volumes of $95 \%$ ethanol. Nick-translation for hybridization probes, agarose gel electrophoresis, and Southern blotting were performed using standard methods (Maniatis et al. 1982). Filter hybridization followed the method of Church and Gilbert (1984). Hybond-N nylon membranes were used for transfer of DNA following gel electrophoresis. Probes were removed from the filter between hybridizations by washing in a solution of $80 \%$ formamide, $10 \mathrm{~mm}$ Tris- $\mathrm{HCl}(\mathrm{pH} 7.5), 12.5 \mathrm{~mm}$ EDTA, $1 \%$ SDS in a shaking water bath at $65^{\circ} \mathrm{C}$. Comparisons of the amount of viral DNA in the starting extracts with the amounts of viral DNA recovered after gel filtration (Fig. 3) and density equilibrium centrifugation (Fig. 4) were done using equal volumes of the corresponding samples. Although these data do not allow a determination of the total recovery in the two experiments, they demonstrate that the specific activity (integration events/linear DNA molecule) of the starting material and the recovered material are roughly equivalent.

\section{Velocity sedimentation gradients}

Continuous sucrose gradients were poured with a twochamber, 15-ml Hoeffer Gradient maker using 15\% and 30\% sucrose solutions in buffer A [ $10 \mathrm{~mm}$ Tris- $\mathrm{HCl}$ (pH7.4), $225 \mathrm{~mm}$ $\mathrm{KCl}, 5 \mathrm{mM} \mathrm{MgCl} 2,1 \mathrm{mM} \mathrm{DTT}, 20 \mu \mathrm{g} / \mathrm{ml}$ aprotinin] and kept on ice. Gradients were overlayed with $0.5 \mathrm{ml}$ of cytoplasmic or nuclear extract and centrifuged at $35,000 \mathrm{rpm}$ for $3 \mathrm{hr}$ at $4^{\circ} \mathrm{C}$ in a Beckman SW-41 rotor. Gradients were fractionated from the top into 12 fractions of $1 \mathrm{ml}$ with a Buchler Densi Flow II apparatus. Polyribosome peaks were detected during the fractionation by absorbance at $260 \mathrm{~nm}$ with an ISCO UA- 5 flowthrough spectrophotometer system. Each lane in Figure 2, A, B, and D, represents one-quarter of the corresponding fraction.

\section{Gel-exclusion column chromatography}

A $200-\mathrm{ml}$ BioRad A5M column $30 \mathrm{~cm}$ in height was equilibrated at $4^{\circ} \mathrm{C}$ with 2 liters of buffer B [ $10 \mathrm{~mm}$ Tris- $\mathrm{HCl}(\mathrm{pH} 7.4)$, $100 \mathrm{~mm} \mathrm{KCl}, 5 \mathrm{~mm} \mathrm{MgCl} 2,1 \mathrm{~mm}$ DTT, $20 \mu \mathrm{g} / \mathrm{ml}$ aprotinin]. The lower salt concentration was chosen to facilitate nuclease treatments in the experiments described below. Integration reactions were adjusted to return salt levels to standard assay conditions. Then, $5.0 \mathrm{ml}$ of cytoplasmic extract was loaded onto the column and $1.5-\mathrm{ml}$ fractions were collected with an ISCO Retriever II fraction collector. The flow rate was $1.0 \mathrm{ml} /$ min. Next, 100- $\mu$ l aliquots of the fractions were diluted to 500 $\mu \mathrm{l}$ in water, and absorbance at $260 \mathrm{~nm}$ was determined with a Beckman DU-40 Spectrophotometer. The absorbance values shown in Figure 3A were corrected for the dilution. Each lane in Figure $3 \mathrm{~B}$ represents $25 \mu \mathrm{l}$ of the corresponding fraction.

\section{Equilibrium density gradients}

A three-step discontinuous gradient was poured using approximately $4 \mathrm{ml}$ each of nuclear extract adjusted to $60 \%, 30 \%$, and
$0 \%$ Nycodenz by mixing nuclear extract with an appropriate volume of $80 \%$ Nycodenz made in buffer A (Nycodenz is a nonionic density gradient medium available from Accurate Scientific and Chemical Corporation). The gradient was poured in a heat-seal tube and kept at $4^{\circ} \mathrm{C}$ throughout all manipulations. Centrifugation was at 50,000 rpm in a Beckman Ti-50 fixedangle rotor at $4^{\circ} \mathrm{C}$ for $8 \mathrm{hr}$. Fractions were collected by dripping from the bottom of the gradient. Density was determined by measuring absorbance at $360 \mathrm{~nm}$ and using the formula: Density $(\mathrm{gm} / \mathrm{ml})=0.135 \times \mathrm{OD}_{360}+1.0$. Density of the peak fraction was confirmed by refractometry. Density values are affected by the fact that macromolecules are hydrated extensively in the nonionic medium. Each lane in Figure $3 \mathrm{~A}$ represents $50 \mu \mathrm{l}$ of the corresponding fraction.

\section{Immune precipitations}

For each sample tested, $300 \mu \mathrm{l}$ of cytoplasmic extract was adjusted to $0.5 \%$ NP- 40 , mixed with $5 \mu$ l of antiserum, and incubated on ice for $1 \mathrm{hr}$. Thirty microliters of $10 \mathrm{mg} / \mathrm{ml}$ Pansorbin (fixed Staphylococcus aureus cells from CalBiochem) was added and again the mixture was incubated for $1 \mathrm{hr}$ on ice. Immune complexes were pelleted for $20 \mathrm{sec}$ in an Eppendorf centrifuge at $4^{\circ} \mathrm{C}$. The supernatants were saved for analysis of viral DNA and integration activity. The immune complex pellets were washed three times with $1.0 \mathrm{ml}$ of buffer A containing $0.5 \% \mathrm{NP}-40$. The final washed pellets were resuspended in 300 $\mu I$ of buffer A with $0.5 \%$ NP-40 and analyzed for viral DNA and integration activity. Each lane in Figure 5 represents $50 \mu 1$ of the corresponding sample. The nonimmune goat serum, the goat anti-MLV (whole virus) serum, and the goat anti-MLV capsid serum $\mathrm{ml}$ were from the Biological Carcinogenesis Branch, DCCP, at the National Cancer Institute. The rabbit anti-MLV capsid sera $\mathrm{ml}$ and $\mathrm{m} 2$, and the goat anti-MLV capsid serum $\mathrm{m} 2$ were gifts from Hung Fan (University of California, Irvine).

\section{Nuclease treatments}

All nuclease treatments were done in buffer B with cytoplasmic extract that had been purified partially by gel-exclusion column chromatography as described above. Micrococcal nuclease (Boehringer-Mannheim) was added to the partially purified cytoplasmic extract, which was then adjusted to $1 \mathrm{mM} \mathrm{CaCl}$ and incubated on ice. Aliquots were removed at indicated times, adjusted to 2 mM EGTA, and kept on ice until all samples were collected. Then samples were analyzed for viral DNA and integration activity. Each lane in Figure 6A represents $50 \mu \mathrm{l}$ of the corresponding sample. For the experiment shown in Figure 7, nuclei were prepared by trypsinizing a confluent monolayer of Rat-1 cells (100 mm in diameter). The cells were washed twice in buffer C [10 mM Tris- $\mathrm{HCl}(\mathrm{pH} 7.4), 100 \mathrm{~mm} \mathrm{KCl}, 1 \mathrm{~mm}$ EDTA, $1 \mathrm{~mm}$ DTT, $20 \mu \mathrm{g} / \mathrm{ml}$ aprotinin], lysed with $0.2 \%$ Triton $\mathrm{X}-100$ in buffer $\mathrm{C}$, the nuclei pelleted at $1000 \mathrm{~g}$, and washed twice with buffer $C$. The final pellet of roughly $5 \times 10^{6}$ nuclei was resuspended in $1.0 \mathrm{ml}$ of buffer $B$ and mixed with $1.0 \mathrm{ml}$ of partially purified cytoplasmic extract. Each lane in Figure 7 represents $250 \mu \mathrm{l}$ of the corresponding sample. For the experiment shown in Figure 8, the restriction digest with BglII and BamHI (New England Biolabs) was done on ice for $3 \mathrm{hr}$ with 100 units of each enzyme in $0.5 \mathrm{ml}$ of partially purified cytoplasmic extract. The digestion was stopped by the addition of $10 \mathrm{~mm}$ EDTA and the sample was loaded onto a $15-30 \%$ sucrose gradient in buffer $A$ and centrifuged for $3 \mathrm{hr}$ at 35,000 rpm in an SW-41 rotor at $4^{\circ} \mathrm{C}$. 


\section{Acknowledgments}

We thank Titia de Lange and Peter Pryciak for helpful comments on the manuscript, and Hung Fan and Stephen Goff for providing antisera. This work was supported by funds from the National Institutes of Health, the G.W. Hopper Foundation, the Howard Hughes Medical Institute, and the Lucille P. Markey Charitable Trust. H.E.V. is an American Cancer Society Research Professor. P.O.B. was a Lucille P. Markey Scholar for a portion of this work and an assistant investigator of the Howard Hughes Medical Institute for the remainder.

\section{References}

Alberts, B. 1984. The DNA enzymology of protein machines. Cold Spring Harbor Symp. Quant. Biol. 49: 1-12.

Boeke, J.D., D.J. Garfinkel, C.A. Styles, and G.R. Fink. 1985. Ty elements transpose through an RNA intermediate. Cell 40: $490-500$.

Bramhill, D. and A. Kornberg. 1988. A model for initiation at origins of DNA replication. Cell 54: 915-918.

Brown, P.O., B. Bowerman, H.E. Varmus, and J.M. Bioshop. 1987. Correct integration of retroviral DNA in vitro. Cell 49: $347-356$

1989. Retroviral integration: Structure of the initial covalent product and its precursor, and a role for the viral integrase protein. Proc. Natl. Acad. Sci. (in press).

Church, G.M. and W. Gilbert. 1984. Genomic sequencing. Proc. Natl. Acad. Sci. 81: 1991-1995.

Craigie, R. and K. Mizuuchi. 1985. Mechanism of transposition of bacteriophage Mu: Structure of a transposition intermediate. Cell 41: 867-876.

DesGroseillers, L. and P. Jolicoeur. 1983. Physical mapping of the $\mathrm{FV}_{\mathrm{V}}-1$ tropism host range determinant of $\mathrm{Balb} / \mathrm{c}$ murine leukemia viruses. I. Virol. 48: 685-696.

Dickson, C., R. Eisenman, H. Fan, E. Hunter, and N. Teich. 1985. Protein biosynthesis and assembly. In RNA tumor viruses (ed. R. Weiss et al.), vols. 1 and 2. Cold Spring Harbor Laboratory, Cold Spring Harbor, New York.

Donehower, L. and H.E. Varmus. 1984. A mutant murine leukemia vinus with a single missense codon in pol is defective in a function affecting integration. Proc. Natl. Acad. Sci. 80: $6461-6465$.

Duyk, G., J. Leis, M. Longiaru, and A.M. Skalka. 1983. Selective cleavage on the avian retroviral long terminal repeat sequence by the endonuclease associated with the form of avian reverse transcriptase. Proc. Natl. Acad. Sci. 80: 67456749.

Echols, H. 1986. Multiple DNA-protein interactions governing high-precision DNA transactions. Science 233: 1050-1056.

Eichinger, D.J. and J.D. Boeke. 1988. The DNA intermediate in yeast Tyl element transposition copurifies with virus-like particles: Cell-free Tyl transposition. Cell 54: 955-966.

Felsenfeld, G. 1978. Chromatin. Nature 271: 115-121.

Freidman, D.I. 1988. Integration host factor: A protein for all reasons. Cell 55: 545-554.

Fujiwara, T. and K. Mizuuchi. 1988. Retroviral DNA integration: Structure of an integration intermediate. Cell 54: 497504.

Grandganett, D.P. and A.C. Vora. 1985. Site specific nicking at the avian retrovirus LTR circle junction by the viral pp32 endonuclease. Nucleic Acids Res. 13: 6205-6221.

Grandganett, D.P., A.C. Vora, R. Swanstrom, and J. Olsen. 1986. Nuclease mechanism of the avian retrovirus pp32 endonuclease. J. Virol. 58: 970-974.

Griffith, J.D. 1975. Chromatin structure: Deduced from a minichromosome. Science 187: 1202-1203.
Jolicoeur, P. 1979. The FV-1 gene of the mouse and its control of murine leukemia virus replication. Curr. Topics Microbiol. Immunol. 86: 67-122.

Kornberg, R.D. 1977. Structure of chromatin. Annu. Rev. Biochem. 46: 931-955.

Lobel, L., M. Patel, W. King, M. Nguyen-Huu, and S. Goff. 1985. Construction and recovery of viable retroviral genomes carrying a bacterial repressor transfer RNA gene. Science 228: 329-332.

Maniatis, T., E.F. Fritsch, and J. Sambrook. 1982. Molecular cloning: A laboratory manual, Cold Spring Harbor Laboratory, Cold Spring Harbor, New York.

Muller, U., H. Zentgraf, I. Eicken, and W. Keller. 1978. Higher order structure of simian virus 40 chromatin. Science 201: 406-414.

Panganiban, A.T. and H.M. Temin. 1984a. Circles with two LTRs are precursors to integrated retrovirus DNAs. Cell 36: $673-679$.

- 1984b. The retrovirus pol gene encodes a product required for DNA integration: Identification of a retrovirus int locus. Proc. Natl. Acad. Sci. 81: 7885-7889.

Roeder, G.S. and G.R. Fink. 1983. Transposable elements in yeast. In Mobile genetic elements (ed. J. Shapiro), pp. 300-328. Academic Press, New York.

Schwartzberg, P., J. Colicelli, and S.P. Goff. 1984. Construction and analysis of deletion mutations in the pol gene of murine leukemia virus: A new viral function required for productive infection. Cell 37: 1043-1052.

Smotkin, D., A. Gianni, S. Rozenblatt, and R. Weinberg. 1975. Infectious viral DNA of murine leukemia virus. Proc. Natl. Acad. Aci. 72: 4910-4913.

Surette, M.G., S.J. Buch, and G. Chaconas. 1987. Transpososomes: Stable protein-DNA complexes involved in the in vitro transposition of bacteriophage $\mathrm{Mu}$ DNA. Cell 49: $253-262$.

Varmus, H.E. 1983. Retroviruses. In Mobile genetic elements (ed. J. Shapiro), pp. 411-503. Academic Press, New York.

Varmus, H.E. and P.O. Brown. 1989. Retroviruses. In Mobile DNA (ed. M. Howe and P. Berg), Amercian Society for Microbiology Publications, Washington, D.C. (in press).

Varmus, H.E. and R. Swanstrom. 1985. Replication of retroviruses. In RNA tumor viruses, vols. 1 and 2 , (ed. R. Weiss et al.). Cold Spring Harbor Laboratory, Cold Spring Harbor, New York.

Varmus, H.E., S. Heasley, K.-J. Kung, H. Oppermann, V.C. Smith, J.M. Bishop, and P.R. Shank. 1978. Kinetics of synthesis, structure, and purification of avian sarcoma virusspecific DNA made in the cytoplasm of acutely infected cells. J. Mol. Biol. 120: $55-82$. 


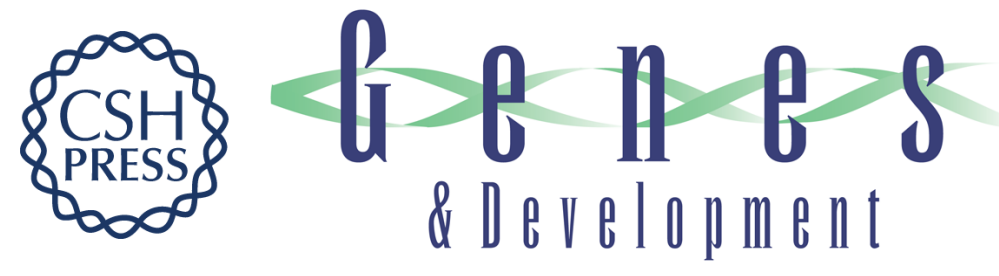

\section{A nucleoprotein complex mediates the integration of retroviral DNA.}

B Bowerman, P O Brown, J M Bishop, et al.

Genes Dev. 1989, 3:

Access the most recent version at doi:10.1101/gad.3.4.469

$\begin{array}{ll}\text { References } & \begin{array}{l}\text { This article cites } 26 \text { articles, } 9 \text { of which can be accessed free at: } \\ \text { http://genesdev.cshlp.org/content/3/4/469.full.html\#ref-list-1 }\end{array}\end{array}$

License

Email Alerting Receive free email alerts when new articles cite this article - sign up in the box at the top Service right corner of the article or click here.

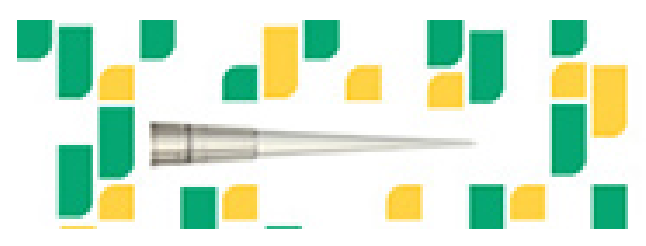

Focused on your science.

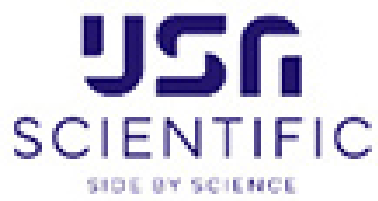

Copyright @ Cold Spring Harbor Laboratory Press 